\title{
Personal Experiences of Oppression of Women Stereotypes in the Middle East: Both East and West are Guilty
}

\author{
Dina M. Abdelzaher, University of Houston Clear Lake, USA \\ Amanda Bullough, Thunderbird School of Global Management, USA
}

The Middle East has always Been filled with unique happenings that are worthy of research, and the region is now more than ever under a research spotlight. In international business research we have witnessed the significant impact of cultural values on both firms and markets. Therefore, we seek to emphasize the importance of pursuing culturally accurate research. We argue that if we really seek to understand the impact of culture and societies in the Middle East as scholars, it is important that we revisit some assumptions or generalizations to ensure that we compensate or control for our own biases. This may be easier said than done, as how we perceive the world will always be guided by what we have seen, experienced, heard, or not. But as many notable researchers conclude, as much as we try to control for our own bias, the personal lens through which we see life when doing research is often more influential than we like to admit (Morrow, 2005; Stiles, 1993). Bias can be difficult to recognize because our thoughts are a product of what we have previously learned. Scholars have long argued that researchers need to recognize that these potential fallacies exist in order to improve the quality of our research in foreign regions and bridge the gaps in levels of understanding between cultures.

It seems obvious that bias might enter the research lens when dealing with cultures with large cognitive, cultural, or physical distances from the researchers. What is less obvious is when biases or assumptions are made from individuals from relatively close societies, in terms of physical, religious, or cultural proximity. The issue of bias can be especially relevant when dealing with women in the Middle East (Saadawi, 2007). This article seeks to shed some light on potential stereotypes that exist about Middle Eastern women (Moghadam, 2003). We focus on the concept of oppression of women to illustrate some of these unintended assumptions, which we argue can be a significant impediment to truth-seeking cultural research.

We aim to show in this article interesting examples of gender stereotyping by individuals coming from cultures that may appear quite similar in many ways, at least from an outsider's point of view. Our insights are driven by a discovery made while conducting research with Afghan and Saudi Arabian women on the role of family and collectivism in entrepreneurial success and intention. Although oppression of women was not a direct focus of this research, reflection on our interviews revealed variations of the concept of women's oppression from multiple perspectives: how individuals in the Middle East might perceive other Middle Eastern cultures, how the individual perceives his or her own culture, and how individuals in the West perceive the Middle East. These insights were revealed when we integrated the perspectives of Saudi and Afghan women on the degree of women's oppression and their respective roles in the business environment. We derive our judgements from interviews of women in the Middle East by both authors.

\section{Interesting Insights Revealed}

This is a story of interaction between Afghan women entrepreneurs and a Saudi Arabian, female MBA student studying in the US. It began with the Saudi student's exposure to culture in Afghanistan through a business plan consulting class. In the class, her team was partnered with an Afghan woman entrepreneur. The student team was charged with working very closely with their client to help research and revise her business model and plan. Toward the conclusion of the class, the Saudi student had an interesting conversation with her professor and shared that she was surprised by how many similarities she found between Afghan women and women in her own country. She was shocked because she always thought of Afghanistan as being so poor and disadvantaged, especially with regard to women, compared to her own country's vast wealth and opportunity. While she recognized the challenges that women in Saudi Arabia face vis-à-vis men, she never thought there would be so many similarities with a culture like Afghanistan. The US-American professor always recognized the similarities beyond the economic differences as quite obvious from her perspective, and she was intrigued by the revelation from her Saudi student.

The story continues early in the next semester with a business training program for Afghan women entrepreneurs on campus in the US. The same Saudi female student is the child of an Iranian mother and a Saudi father, a unique marriage by Saudi Arabian standards that exposed her to more cultural differences growing up than is typical there. She speaks fluent Farsi and volunteered to assist with interpreting and translations while the Afghan women were visiting (the Afghan language of Dari is very similar to Farsi). Throughout the two weeks that the Afghan women 
were on campus, they bonded with the Saudi student and spent time getting to know each other and one another's cultures. Toward the end of the experience, one of the Afghan women expressed to the Saudi woman, in a sympathetic tone, how sorry she was for her because of the oppression that Saudi woman face. The Saudi woman was again surprised, and even more so this time. She thought of Afghan women as oppressed and couldn't believe that they would pity her because of the oppression they perceived of Saudi women. She had always recognized Saudi woman as having to fight for gender equality and facing strong gender biases in the workplace, but she had never thought of Saudi woman as "oppressed," and certainly not by Afghan standards. She had spent five years living and studying in the US, and no one had ever used that word when referring to women in her country, although compared to US women, many would say this is so. US-Americans had asked her about cultural issues, like why women are not allowed to drive, which in the US is seen in many ways as a rite of passage and a means of freedom. She always explained that it's not that big of a deal, women do just fine without driving, and there are bigger issues to worry about. It never occurred to her that US-Americans might have thought of Saudi women as oppressed. This word, oppressed, represented a powerful revelation for her. She began to wonder, "Are women in Saudi Arabia really oppressed? Is this how the world sees it?"

What is interesting is the discovered difference of perspective between women from two Middle Eastern countries. The irony is that although many in the US may think of Saudi women as oppressed, no one had ever used that word with her, maybe simply out of being polite. An informal interview with a second Saudi Arabian woman revealed that she also did not see Saudi women as oppressed at all, except she was aware of the stereotype. She was nonetheless convinced that Saudi Arabia's government attention to the development of women has been demonstrated in many of their initiatives.

Here we have two countries in the Middle East, speaking different languages, yet both rooted in Islamic heritage, whereby religious principles are not separated from everyday practices. The countries lie at extreme ends of economic development, with Afghanistan being one of the poorest countries in the world and Saudi Arabia being one of the richer in terms of per capita GDP. Yet people from around the world may categories both as countries where women are oppressed, and where men, and perhaps women, need liberation of thought. It appears that these assumptions are not only made by individuals in the West about individuals in the East, as is most notably discussed, but they are also made by individuals in the East about their neighbors in the East. Assumptions, stereotypes, biases, and generalizations are made by individuals all over the world with relation to societies that are different from their own.

\section{The Word Oppression}

If oppression is the term being used in this context, then is it defined in the same way in the East as in the West, or even among societies? Do our definitions fit other cultures? What levels of oppression are likely to impact the business environment of women entrepreneurs? Who is best equipped to recognize this? What economic aspects are affected by this oppression? Does it matter that people within a society don't view themselves as oppressed, when outsiders do? Is oppression even the right term to use?

While many would agree that women face obstacles in conducting business in different parts of the world, it is important that we seek to understand these differences and the nuances between them in the Middle East region.

\section{What Can We as Scholars Learn from This?}

While scholars know to be careful of letting biased assumptions enter their research frame (Hunter \& Schmidt, 2004), the human brain is fallible and driven by forming shortcuts to process large amounts of information, like selective perception (Beyer et al., 1997), based on the perceiver's background, experiences, and attitudes; stereotypes (Hilton \& von Hippel, 1996), attributing qualities to a person based on the perception of a group; profiling (Robbins \& Judge, 2008), judging a group of individuals based on one characteristic that we have been exposed to either through media or personal accounts and experiences. Generalizations are means through which the brain naturally processes large amounts of information, but they become a problem when we pass judgment or build new thought patterns based on potentially inaccurate information (Robbins \& Judge, 2008). While this is part of human nature, it is most dangerous when scholars subconsciously bring these stereotypes into their approach to research. In this article, we remind researchers and journal reviewers to dig deep and question our assumptions before we design studies and make recommendations.

While research has highlighted that women face different sets of obstacles in economic life (e.g., Muravyev, Talavera, \& Schäfer, 2009; Prasad, 2009), the question is, can we accurately describe these obstacles through Western institutionalized lenses? When reflecting on some of these insights, a series of potential research questions comes to mind. We summarize below some of these insights and raise some questions that could potentially guide future cultural research questions within the context of women in emerging economies, particularly those of the Middle Eastern region.

\section{Revisiting Western-Based Assumptions}

\section{Are Women in Muslim Countries Oppressed?}

Many would say yes. But if so, how do we know? What would it take for us to recognize true oppression? Are we getting too caught up in cultural indicators, like women not driving? What if women weren't allowed to drive because society viewed it as protecting and taking care of women by driving for them? Would that change the perception of oppression? 
By asking these questions, do we lose sight of other angles that we can study to help us really understand how women live their lives and the hidden barriers and facilitators of engaging in the business environment? Once oppression is clearly defined, how is this likely to affect how women become successful business leaders and entrepreneurs? What are the differences across Middle Eastern countries and across female segments of the same country? How do we best measure the impact of oppression on the economic and leadership activities of women in the Middle East?

\section{Who Is Best to Identify Oppression?}

Does it exist if the person described as oppressed doesn't recognize it as oppression? Or, does it become real when others bring it to the attention of an unsuspecting subject that she might in fact be oppressed. Which is more accurate? Can someone accept that they are oppressed when they do not feel that way? Or is oppression something that is so embedded in a culture that the person being oppressed cannot recognize it? The label could be a real eye-opener for the individual, or incredibly insulting. In other words, are we doing the person a favor by describing and maybe even convincing them that they are oppressed? By doing so, are we simply passing on the labels and stereotype we have and transferring these ideas across boundaries? Is this the most effective way for us to better understand other cultures? Or is this moving us even further away from understanding other societies? Perhaps the value assigned to a word like oppression is at play, with some cultures thinking it has a more suggestive connotation than others.

\section{Revisiting Eastern-Based Assumptions}

\section{How Do Middle Easterners Perceive Oppression?}

When asking women from other Middle Eastern countries if they think that Saudi women are oppressed, it might be surprising to learn that many Middle Easterners would not agree. While some aspects of social life may seem oppressive, if they are an accepted part of the local culture, they are the accepted norm. If that is the case, is there evidence of oppression? In other words, if the person has accepted these social norms, is it fair to call this person oppressed? Is acceptance of social norms a choice? If we were to ask Middle Eastern women if Western women are oppressed, they might come up with very interesting insights depending on how they define oppression. We've learned here that there is variation among how different cultures view oppression. Even among Muslim countries we are finding different perspectives of oppression, which are likely to differ in accordance with the individual's home country. It matters how we define oppression and whether the definition we use is accurate for reflecting reality in all of the Middle East.

What drives women of the same region and faith, who may be described by the world as oppressed, to see these differences among one another? Are these differences real or again a stereotype existing in this region of Middle Eastern countries? Are the women possibly observing differences that other distant observers may not be aware of? Can we researchers identify the factors behind these differences to better understand the cultural variations among women in Middle Eastern countries?

Why was the Saudi woman never told that Saudi Arabia was oppressive before meeting the Afghan women? Was it because individuals in the US were being polite, or was it because her Western friends and colleagues over the years would have a used a different word? Was it possible that many US-Americans she came in contact with simply never gave it more thought beyond their simple observations, like Saudi women not driving? Or was it because they did not find her opinions, attitudes, beliefs and behaviors to fit the stereotype of "oppressed" Saudi Arabian women.

Why is the lack of women driving such a salient indicator of oppression in Saudi Arabia among individuals in the US? Another Saudi woman explained that most families have drivers that reside on the premises. It is customary in that culture that the driver will take you where you need to go. Many women would love the idea of having someone to drive them places, freeing them to busy themselves in the car with other tasks. In a country like the US, driving is a means of physical freedom and hired drivers are cost prohibitive. Only among the extremely wealthy or in business interactions will one find a hired driver, and then it is a status symbol. For US-Americans, the issue of women driving in Saudi Arabia relates to the fact that, because women are not allowed to have driving licenses, driving is therefore illegal. Perhaps it's the illegality that strikes foreigners as oppressive. Afghan women don't drive either, although the restriction is cultural, not legal.

Which women related factors are culture-driven and which ones are religion-based? Are the citizens of these countries aware of such variation? Does such awareness impact their behaviors? What factors are behind the variation between the religious vs. culture scale that exists in the region and impacts behaviors? For example, the Saudi Arabian law on women driving is not presented as prescribed by Islam, it is the law of that country. As researchers, it is important that we make such a distinction to understand the roots, depth, embeddedness, and possibility of change of various social phenomena. The Islamic faith prohibits all forms of oppression but makes the distinction that men and women are equal but play different roles. What does this really mean and what are the business implications of this principle?

\section{Conclusions}

From a research standpoint, some work has been done to better understand culture-women and culture-Middle East relationships, although very little. As international business scholars, if we want to further business in the Middle East region, we need to make much more concerted efforts to conduct high quality, empirical research on culture in the region. In a recent conversation, an Afghan woman said:

Culture is ingrained in everything from the day you're born. 
In fact, it affects a woman's life in particular even before she's born, even before she's conceived. The marriages of her mother's children can be determined when her mother's marriage is being arranged, long before she is even pregnant with those children. This shows how much culture plays into the control one has over her life.

The purpose of this article is not to make the case that women in Middle Eastern countries are not at all oppressed, or that they all are and may not know it. Like in all cultures, including in the West, there are likely to be different segments of women that are subjected to different forms of oppression. We need to seek to understand this within Middle Eastern cultures, regardless of what region we come from. Perhaps the greatest value in conducting cross-cultural research is to discover the intricacies regarding what is unique about constructs like oppression across countries in the same region.

Beyond oppression, we need to expand our perspectives to account for recent developments in the Middle East. Significant changes can present opportunities for the role that women play in society. Many government initiatives have demonstrated their support for women to become more active economic contributors, as economic resources become scarcer. This changing role is very much driven by economic pressures that have compelled women to start working and share in family financial support. Perhaps it is because of this that we are seeing men become more accepting of sharing the workplace with women. Even though, as the Saudi student in our story admits, there is a lot of work yet to be done for gender equality.

This short paper seeks to highlight the importance of being aware of our stereotypes, which can emerge from both the West and within the East, and revisit these assumptions. In doing so, scholars and policy makers together can arrive at more effective and appropriate developmental tools for helping women enhance their economic and leadership contributions to the prosperity of their nations.

\section{References}

Beyer, J. M., Chattopadhyay, P., George, E., Glick, W. H., Ogilvie, d., $\&$ Pugliese, D. 1997. The selective perception of managers revisited. Academy of Management Journal, 4(3): 716-737.

Hilton, J. L., \& von Hippel, W. 1996. Stereotypes. Annual Review of Psychology, 47(1): 237-271.

Hunter, J. E., \& Schmidt, F. L. 2004. Methods of meta-analysis: Correcting error and bias in tesearch findings (2nd edn). Thousand Oaks, CA: Sage

Moghadam, V. M. 2003. Modernizing women: Gender and social change in the Middle East. Boulder, CO: Lynne Rienner Publishers.

Morrow, S. L. 2005. Quality and trustworthiness in qualitative research in counseling psychology. Journal of Counseling Psychology, 15(2): 250-260.
Muravyev, A., Talavera, O., \& Schäfer, D. 2009. Entrepreneurs' gender and financial constraints: Evidence from international data. Journal of Comparative Economics, 37(2): 270-286.

Prasad, R. M. 2009. Loan hurdles: Do banks discriminate sgainst women entrepreneurs? The Academy of Management Perspectives, 23(4): 91.

Robbins, S. P., \& Judge, T. A. 2008. Perception and individual decision making. In S. P. Robbins \& T. A. Judge, Organizational behavior. Upper Saddle River, NJ: Prentice Education.

Saadawi, N. E. 2007. The Hidden Face of Eve: Women in the Arab World (2nd edn). New York: Zed Books.

Stiles, W. B. 1993. Quality control in qualitative research Clinical Psychology Review, 13(6): 593-618.

Dina Abdelzaher is an Assistant Professor at University of Houston Clear Lake. She earned her Doctoral degree from Florida International University. Her research is mainly in the area of Global Strategy, with specific interests in corporate social/environmental issues and global entrepreneurship. She is widely published in prestigious national and international conferences and journals. Dr. Abdelzaher's research was awarded the "Kauffman Doctoral Assistant Grant Award 2011" on the examination of the relationships between global mindsets, entrepreneurship orientation, and individual innovation, and also received the "William J. Ziegler Award 2009" at AIB-Southeast. She worked for leading multinational corporations in the Middle East (Egypt) for several years in market research and corporate consulting.

Amanda Bullough is an Assistant Professor of Entrepreneurship and Leadership at Thunderbird School for Global Management in Glendale, Arizona. Her widely published research spans entrepreneurship, leadership, crosscultural management, and international development. She presents on Leadership and Entrepreneurship at numerous international business and management conferences. She won the WAIB Best Paper award for Increased Gender Awareness in International Business Research at the AIB conference in 2009. Recent streams of research include entrepreneurship in war zones and under adverse conditions, and global mindset and leadership in teams. Dr. Bullough is also the Academic Director for the Goldman Sachs 10,000 Women Entrepreneurship training programs in Afghanistan and Peru. 